\title{
Skinner and the Rise of Behavior Modification and Behavior Therapy
}

\author{
Francisco Javier Labrador \\ University Complutense of Madrid
}

\begin{abstract}
Skinner is, without a doubt, one of the most predominant figures in the development of Behavior Modification and Behavior Therapy. Skinners' work is essential to the development of Behavior Modification and Behavior Therapy. Beginning with the social need for efficient psychotherapy, and after having generated a solid theoretical body of behavioral laws, Skinner indicated and also developed the appropriate path towards efficient interventions for unadaptive behavior. He developed a new theory regarding abnormal behavior (psychopathology), as well as a procedural model for evaluation (diagnosis) and intervention: "The functional analysis of behavior". His applications for this kind of work are pioneering and at the same time, he is the agglutinant figure of what we today call "Behavior Modification and/or Therapy".

It is remarkable that a scientist could change the theories and practices of a discipline as radically as Skinner and his work did. His work, however, still has its limitations. The best way to acknowledge and pay tribute to Skinners' work is to overcome these limitations. Keywords: Skinner, behavior modification, behavior therapy
\end{abstract}

Skinner es sin duda una de las figuras determinates en el desarrollo de la Terapia y Modificación de la Conducta. La obra de Skinner resulta determinante en el desarrollo de la Modificación y Terapia de Conducta. Partiendo de la necesidad social de una psicoterapia eficaz, y después de haber generado un sólido cuerpo teórico de leyes del comportamiento, indica y también desarrolla el camino adecuado para la intervención eficaz sobre las conductas desadaptadas. Desarrolla una nueva formulación sobre las conductas anormales (psicopatología), así como un modelo de procedimiento para la evaluación (diagnóstico) y la intervención: "El análisis funcional de la conducta". Suyos son también los aplicaciones pioneras de esta forma de proceder y asimismo es la figura aglutinante de esta forma de actuación que hoy denominamos "Modificación y/o Terapia de Conducta".

Es impensable que un científico pueda cambiar de manera más radical el conocimiento y en las prácticas de una disciplina que lo que ha supuesto la obra de Skinner. No obstante su obra obviamente refleja limitaciones, por lo que el mejor reconocimiento y homenaje a la obra de Skinner será superar estas limitaciones.

Palabras clave: Skinner, Modificación de la conducta, terapia de conducta

Correspondence concerning this article should be addressed to Francisco Javier Labrador, Departamento de Personalidad, Evaluación y Tratamiento, Campus Somosaguas, 28223, Madrid (Spain). E-mail: flabrador@psi.ucm.es

Translation: Jean L. Feuerstein 
Skinner's importance to Behavior Modification (BM) and Behavior Therapy (BT) is substantial, as it is backed by the importance that experimental analysis of behavior has in the methodological development of BM, or that an important part of the techniques used in BM are based in operant conditioning, and specifically, practical developments that were fundamentally made because of Skinner's work. Some of Skinners' other outstanding views include his programmatic defense of psychotherapy from an alternative perspective of traditional models. He also believed in the past and present relevance of the defended methodological approach: the intra-subject replication or the $\mathrm{N}=1$ designs.

Skinners' contributions are important not only because of his findings, but because of the volume of his work and the areas it covers. Because of his contributions, Skinner can be considered one of the antecedents of BM since part of his work and contributions came before BM was developed and/or influenced it's development. On the other hand, and of no less importance, his developments came during the rise of $\mathrm{BM}$ in which he collaborated in a decisive manner, (including giving BT its name ${ }^{1}$; Skinner, Solomon and Lindsley, 1953). Lastly, developments continued when BM was already established as such, making Skinner an inspiration to, and alma mater of, one of the most important orientations of BM: Applied Behavior Analysis.

The aim of this paper is to try to point out some of Skinners' most important contributions to the development of BM, especially during its conception and throughout its development.

\section{A Starting Point: The Social Need}

Behavior Modification came about as an alternative to the concepts or theoretic models of abnormal behavior as well as the applied intervention in this field. Psychotherapy is the term traditionally used when referring to this kind of intervention. Different conditions or events contributed to its development, including the following:

- The existent models of abnormal behavior, which came from science or non-psychological disciplines, did not permit adequate integration of the psychologists' knowledge. This limited his work to imitating or complimenting procedures that had nothing to do with his professional training and proved to be useless. (Yates, 1970).

- The existing treatments derived from these models were lengthy, costly, and worst of all, ineffective, with the additional problem of not considering any type of evaluation which would permit correcting procedures. As a consequence, useless and superstitious practices continued (Eysenck, 1952, 1965, 1966).
- The social demands of rehabilitation and care for large groups of people, especially after the second world war, which underlined the importance of interventions capable of effectively treating patients in a short amount of time.

- Having a solid body of scientific knowledge regarding the behavior of organisms which permitted outlines of alternative solutions to these demands. It also allowed for a new way of understanding abnormal behavior and, as a consequence, new explanatory models.

- The initial success in translating this body of laws of behavior into procedures used to modify behavior in inferior animals and in some sporadic applications to human subjects.

- Psychologists' dissatisfaction with the role they had up to this time as "helper" or slave" to a professional who did not achieve significant positive results through his own methods, but would not allow the psychologist to practice his.

We could basically summarize these considerations into two; 1) the social demand to recover a large number of people with behavioral problems, along with the inability of existing psychotherapies to satisfy the demand, and 2) the availability of a body of knowledge which would permit alternative solutions to be established.

Although the conditions were present, what was needed at this time, was someone to come forward, lead the way, and dare to take the first step successfully. Even half a century later, no one would doubt that Skinner was one of those who led the way and took those first steps- successfully, of course.

\section{The Problem: Going From the Laboratory to Real Life}

\section{Developing a Solid Theoretical Body Regarding Behavior}

It was mentioned, in the previous section, that Psychology now held a solid body of scientific knowledge regarding behavior in organisms, which permitted outlines of alternative solutions to abnormal behavior problems. A very important part of the development of this body of scientific knowledge is due to Skinners' work. The following examples, at the very least, are worth highlighting:

1. First of all, his insistence for the need to explain behavior on its own level. He opposed mentalist considerations or explanations as well as physiological explanations. He felt that descriptions and explanations for behavior should be on their own level (observable and operative).

2. His rejection of theory, which he considers as something constructed to compensate for the inadequate data or imperfect or non-existent control over the subject

1 The terms Behavior Modification and Behavior Therapy are used interchangeably for the same idea. In what follows, only the term "Behavior Modification" will be used. 
being studied. Therefore, his theory's rejection was based on considering theory just only a consequence of the lack of understanding or control of phenomena.

3. As an alternative, he proposed adequate behavior analysis consisting of a study of cause and effect relationships. If we can identify the causes of behaviors, and adequately manipulate them, we could demonstrate their control in behavior. If we demonstrate this control, theory would prove unnecessary.

4. To achieve his goal, he proposed the methodological approach of studying individuals as opposed to groups. Intrasubject replication designs (Sidman, 1960) would become the methodological model to follow.

5. Clarification of the two different types of conditioning, respondent and operant, in agreement with the kind of response involved. This made the explanatory procedures of learning clear and made controlling behaviors easier.

6. The development of a large part of the theoretical body of Operant Conditioning, emphasizing the study of reinforcement and the importance of the way it is applied (reinforcement scales).

7. The emphasis of Operant Conditioning, as opposed to Respondent Conditioning, as a process of reference to explain a large part of an organisms' behavior.

8. Lastly, his defense of the generalization of the laws of conditioning: normal and "abnormal" behaviors follow the same principles and laws.

\section{The Question of Controlling People}

Behavioral laws have already been developed which allow us to explain, predict and control the behavior of organisms. The majority of the work done in this area of behavioral control has been done in animals. So, there are two questions presented here: Will this work serve as applicable and efficient to explain, predict and control human behavior? The second question is, if it is applicable, is the control of human behavior ethical and/or desirable? The first question is quickly resolved by pointing out that the scope of application of these laws includes "the behavior of organisms". The second, whether controlling human behavior is ethical or desirable, raises an important controversy.

Although the people has always tried to control human behavior in accordance with certain laws or rudimentary procedures, Skinner (1953) believed that the scientific study of behavior had reached a point where it could provide additional techniques that were more precise and powerful. There was no guarantee, however, that these techniques would always be used in "the best interests of mankind". Did it make sense to develop techniques to efficiently control human behavior without being concerned of how these techniques might be used?. How could we be sure they we would be used in the best interests of mankind and not as imposition strategies for an absolute power?
Different views are expressed when it comes to answering these questions. One of those is that it will never be possible to truly control humans. Obviously, to deny a problem is not the best way to resolve it.

Another alternative is the deliberate rejection of the opportunity to control, or deny control. The "laissez faire" philosophy is an example of this alternative. However, the reality is, denying to accept responsibility of control only implies that we leave control in the hands of others or those of fate. It is hard to believe that fate, in the majority of cases, is the best form of control.

A third possibility, the existence of a central control institution (probably a government) which regulates the ability to control others. However, this brings about the problem of possible absolute power or totalitarianism of the institution.

A fourth solution is to diversify control. We could distribute the control of human behavior among many institutions that have little in common, and that would not come together to form an absolute power. In this way, one institution would control another and while a balance was maintained between them, exploitation by any one particular institution would be avoided. This might be a solution, albeit a partial solution, for those who fear the wrongful use of the science of human behavior. By amply distributing scientific knowledge related to behavior control, we have a certain degree of assurance that it will not be monopolized by any one institution for its own personal gain.

The correct solution seems evident. Since, whether it is recognized explicitly or not, procedures used to control the behavior of others is used on a daily basis by social institutions as well as individuals, and given that improper use of control procedures leads to unrest and anti-control reactions towards those who are trying to control, it seems appropriate to make adequate control techniques available to all institutions and people. Providing institutions such as governments with the most adequate control techniques, would allow more effective planning and prove less costly in terms of personnel. Teaching these techniques to the general population, among those, techniques used by the government, would allow the people to be aware of and defend against a possible misuse or abuse of the techniques. When institutions and individuals practice adequate control techniques, problems caused by those who use them incorrectly will decrease.

The problem resides in who should decide the consequences or final objectives that control should be focused on. Which ethics or morals should the establishment of objectives be based on and who should create them? The answer isn't easy. When an individual manipulates the variables which determine the behavior of another, in an obvious way, we say that the former controls the latter, but we don't ask who is controlling the former. When a government conspicuously controls its people, we consider it a given without considering the events that control the 
government. The answer seems obvious: The environment controls the individual although the individual alters the environment. The culture or social group, pressures or controls the government. The general hypothesis is always the same: A different physical or cultural environment creates a different man. As Skinner pointed out:

"The scientific study of behavior not only justifies raising the general pattern of such proposal; its promises new and better hypotheses. The earliest cultural practices must have originated in sheer accidents. Those which strengthened the group survive with the group in a sort of natural selection. As soon as men began to propose and carry out changes in practice for the sake of possible consequences, the evolutionary process must have accelerated... A further acceleration is now to be expected. As laws of behavior are more precisely stated, the changes in the environment required to bring about a given effect may be more clearly specified... This is no time, then, to abandon notions of progress, improvement or, indeed, human perfectibility. The simple fact is that man is able, and now as even before, to lift himself by his own bootstraps. In achieving control of which he is part of, he may learn at last to control himself." (Skinner, 1961, p. 4).

The problem seems to be adequately directed. There is a sound theoretic body and justification for the application of human behavior control. This justification implies the possibility of applying control to all kinds of behaviors including those traditionally labeled "pathological" or abnormal. However, the application of these new procedures also implies an alternative concept to what we understand as abnormal behavior and what the task of the behavior modifier will be.

\section{The Proposal of Science and Human Behavior} (1953)

The initial proposal and planning of the new concept and form of intervention in the field of abnormal behavior would come from Skinner himself. This proposal was explicitly formulated in his 1953 book, Science and Human Behavior.

In this book, Skinner specifically explained an alternate program of behavior to the psychopathological and psychotherapeutic models of the time. We should remember that Dollard and Miller's attempt (1950), three years before, in their book, Personality and Psychotherapy, did not involve a new orientation, but a translation of psychology of learning terms that were already being created.

\section{The Psychotherapy Field of Study}

In the beginning, Skinner agreed with the idea of control exercised by different institutions or social groups (government, family, businesses, etc.). These groups control the behavior of individuals restricting those who are egotistical and giving them social value. However, in some cases, this control generated certain by-products or "abnormal behaviors" that did not represent an advantage to those in control, and this was often harmful to the individual as well as the group. As Skinner pointed out:

"These by-products of control, which incapacitate the individual or are dangerous either to individual or to others are the special field of psychotherapy" (Skinner, 1953, p. 361).

In consequence, we should understand psychotherapy as an institution that exercises control in the sense of trying to recover or modify behavior or behaviors (of certain people) that are not perceived as advantageous to the controller, and can be harmful to the individual or the group. It is not an institution with such organized control such as a government or religion, but a profession whose members apply more or less standardized techniques. It has already become an important source of control in the lives of many people. As another source of control of human behavior, psychotherapy could have benefits from the advances of the behavior science. Skinner explained it with precision when he describes Psycotherapy as the process of positive consideration which strengthens behavior patterns that were probably punished ("suppressed"). In the same way, he talked about Psychopathology describing how certain personal histories produce individuals whose behavior becomes harmful or dangerous to them or to others.

In accordance with this viewpoint, we consider that:

1. Abnormal or dangerous behaviors, characteristic of mental illness, might have been learned.

2. Abnormal behavior is identical to normal behavior (subject to the same kind of control).

3. The etiology of mental illness and the possibility of therapeutic analysis and change are included in the field of psychology.

\section{Diagnosis}

The Skinner's ideas about diagnosis were well explained in the early 50' when he pointed out that sometimes we take it for granted that the diagnosis, considered to be a mere compilation of information about the patient, is the only point in which behavior science can be useful in the therapeutic process. Once all the facts about an individual have been collected, treatment decisions are left to the therapists' good judgment and common sense The compilation of facts is only the first step in a scientific analysis. The second is to demonstrate functional relationships. When independent variables are under control, these relationships lead directly to the control of the dependant variable. In the present case, control means therapy (Skinner, 1953) . 
As opposed to traditional diagnosis, Skinner proposed the Functional Analysis of Behavior. Its' objective was not only to identify and classify behaviors, but also to identify the variables which control the execution of these behaviors and demonstrate this control, which would indicate the direction treatment should take in order to modify these behaviors.

\section{Treatment}

"The steps which must be taken to correct a given condition of behavior follow directly from an analysis of that condition. Whether they can be taken will depend, of course, upon whether the therapist has control over the relevant variables." (Skinner, 1953, p. 368).

About treatment, the Skinner's point of view coul be summarized in the following points:

- Therapy does not consists of eliminating an impulse that causes problems, but of introducing variables that compensate or correct a history which has produced unfavorable behavior.

- The measures that should be taken to correct a determined circumstance of behavior is deduced from an analysis of that circumstance.

- The possibility of taking these measures depends on if the therapist controls relevant variables.

- The underlying emotion is not a cause of behavior disorders, but a part of them.

- The therapist is a "non-threatening audience" so that emotional behaviors associated with punishment are extinguished.

"Therapy does not consist of releasing a trouble-making impulse but of introducing variables that compensate for or correct a history which has produced objectionable behavior. Pent-up emotion is not the cause of disordered behavior; it is part of it." (Skinner, 1953, p. 378-379)

What has been stated so far, (Skinners' main views), agrees with the idea that "by-products" or "abnormal behaviors" have been produced as a consequence of inadequate control. They are almost always a consequence of aversive procedures, but Skinner also proposed another kind of proceedings.

There are many others ways in which behavior which calls for remedial action may be corrected. When the difficulty cannot be traced to the excessive use of punishment or to other aversive circumstances in the history of the individual, different therapeutic techniques must be developed. There is the converse case, for example, in which ethical, governmental, or religious control has been inadequate... Therapy will then consist of supplying additional controlling variables. When the individual is wholly out of control, it is difficult to find effective therapeutic techniques. Such an individual is called psychotic. (Skinner, 1953, p. 379-380)

Sometimes the therapist must construct a new repertoire which will be effective in the world in which the patient finds himself. Suitable behavior already in the repertory of the may needs to be strengthened, or additional responses may need to be added. Since the therapist cannot foresee all the circumstances in witch the patient will find himself, he must also set up a repertoire of self-control through which the patient will be able to adjust to circumstances as they arise. Such a repertoire consists mainly of better ways of escaping from the aversive self-stimulation conditioned by punishment...As another source of problems, the individual may have been, or may be, strongly reinforced for behavior which is disadvantageous or dangerous.... One obvious remedial technique for behavior which is the product of excessive reinforcement is to arrange new contingencies in which the behavior will be extinguished. (Skinner, 1953, p. 380-381)

Other sources of problems and possible treatments are the following:

- The individual is, or has been, intensely reinforced for performing harmful or dangerous behavior; in this case it's necessary to create new possibilities in which the behavior can be extinguished.

-When the ethical, religious or governmental etc., control has been inadequate, it's necessary to supply additional variables of control.

- Given that we cannot control all circumstances, the possible solution is to develop a repertoire of self-control.

- When the individual finds himself completely out of control, it is difficult to find efficient therapeutic techniques. This individual is called psychotic.

However, he points out some problems with this position:

The field of psychotherapy is rich in explanatory fictions. Behavior itself has not been accepted as a subject matter in its own right, but only as an indication of something wrong somewhere else. ... Above all, it has encouraged the belief that psychotherapy consists of removing certain inner causes of mental illness...

... The task of therapy is said to be to remedy an inner illness of which the behavioral manifestations are merely "symptoms".... In any case, the variables to be considered in dealing with a probability of response are simply the response itself and the independent variables of which it is a function. We have no reason to appeal to pent-up behavior as a causal agent. (Skinner, 1953, pp. 372-374)

The emphasis on observable behavior being accepted as the critical objective of therapeutic change became one of the most important milestones in the development of 
BM. In accordance with his "radical behaviorism" philosophy, the manifested behavior was considered to be the only acceptable objective of scientific investigations. As opposed to methodological behaviorism, the radical behaviorism does not leave out the private facts just because there is no public agreement over the issue. Moreover, as Wilson and O'Leary (1980) emphasize, radical behaviorism does not deny the possibility of auto-observation or selfknowledge, or their possible usefulness, but it questions what we feel or observe and, therefore, what we know. We do not call these facts unobservable and we do not discard them for being subjective. We simply question the nature of the observed object and the trustworthiness of the observations. The main point is not whether subjective experience exists (images, thoughts and feelings), but the role they play in controlling behavior. Skinner himself pointed out how private events should be included in the experimental analysis of behavior. "Adequate behavior science must consider the events that occur within the skin of the organism...as one more part of its behavior." (Skinner, 1963) The final position can be established in the following way: What one feels or observes introspectively is not a world of non-physical nature of consciousness, the mind or mental life, but the actual body of the observer. (Skinner, 1974)

\section{The First Applications of Operant Conditioning}

\section{The Rise of Behavior Modification}

Although the first attempts to treat disorders of learning behavior took place in the 20's and 30's in the United States, these attempts were sporadic and were primarily based on classic conditioning applications (see Mayor and Labrador, 1984). The development of BM, as such, was not sporadic, but continuous and in rapid progression, not only in the number of applications, but also in the variety of problems it was applied to, and was based on the attempt to apply knowledge derived from Operant Conditioning. In broader terms, the development of the applications emphasize a systematic advance, beginning with conceptual extensions and formalizations (Keller and Schoenfeld, 1950;Skinner, 1953, 1957; Fester, 1953, etc.) while also initiating the application of operant methodology to experiments with human subjects. Studies regarding verbal conditioning (Taffel, 1955) were especially important to progressing to clinical applications (Fuller, 1949; Skinner, Solomon and Lindsley, 1953; Lindsley, 1956; Bijou, 1955,1957; Krasner, 1955).

It seems appropriate that we should mention some of the first work done in applying operant conditioning to the modification of "abnormal" behavior. Firstly, that of Fuller (1949), which would be the first to apply operant conditioning in the clinical setting. In this study, operant conditioning was used in the case of an 18 year old considered to be a "vegetative idiot". They selectively reinforced movement behaviors (raising the right arm) using the introduction of sweetened milk into the mouth as reinforcement. Four sessions were sufficient to establish the behavior and demonstrate the control the reinforcing stimulus had on it. Afterwards, they removed the reinforcing stimulus, effectively achieving extinction of the learned movement.

In 1953, Skinner and Lindsley completed an investigation to demonstrate the possibility of applying operant conditioning techniques to patients diagnosed as psychotic at Metropolitan State Hospital (Walthan, Massachusetts). They designed a room functionally similar to Skinner's Box which allowed for a free operant discharging a piston which was recorded by an accumulative register. The room had a window allowing the passage of reinforcements (cigarettes, candy, projection photographs...) depending on the behavior performed. Published reports (Skinner, Solomon and Lindsley, 1953; Skinner, 1954; Skinner, Solomon, Lindsley and Richards, 1954) emphasize the appropriateness of this kind of intervention and point out the achievements made. Also, in the first of these reports, the term Behavior Therapy appeared for the first time.

Lindsley, who continued these investigations, later commented on the advantages of applying these procedures to psychotherapy; in 1963, Lindsley pointed out in 1963 that operant methods are especially suitable for problems in psychotherapy because both fields: 1) emphasize control and behavior modification; 2) treat individuals; 3) use the frequency response per time period as data; 4) focus on the consequences of behavior; and 5) are interested in the dynamic and functional relationship between individuals and their social and non-social environments.

\section{The Organization of Behavior Modification in the United States}

Quickly, Operant Conditioning applications began to increase and a trend developed into what we call BM. The basic formation underlying this type of approach, that was previously known as Applied Behavior Analysis, is that the majority of behaviors considered to be pathological are behaviors that subjects have learned in order to adapt to a particular environment. However, these behaviors are no longer adaptive because the society in which they live disapproves of them. Intervention must be directed towards modifying these behaviors, substituting them for more adaptive behaviors. Given what we know about the laws which regulate behavior learning, maintenance and extinction, the task of the behavior modifier would be to change the keys and contingencies that control the behavior. The subject would then stop performing the undesirable behavior and perform adaptive behavior instead. 
The applied developments that followed these guidelines multiplied rapidly. Bijou (1959, 1963) extended Operant Conditioning techniques to evolutionary problems and mental deficiency; Barret and Lindsley (1962) applied them to mentally retarded children; Baer (1962) to children with illsuited habits such as sucking their thumb; Fester and DeMyer (1961) to autistic children; Flanagan, Goldiamond and Azrin (1958) to cases in stuttering; Barret (1962) to adults with tics; Staats, Staats, Schultz and Wolf (1962) and Staats, Finnley, Minke and Wolf (1964) to different cases of deficiencies, and a long list of etc's. Of all these applications, Ayllons' programs in the hospital environment (Ayllon and Michael, 1959; Ayllon and Haughton, 1964; Ayllon and Azrin, 1965,1968) stand out the most, as well as Bijou's programs with children in the clinical and educational environments (including work by Birnbrauer, Bijou, Wolf and Kidder, 1965; Bijou, Birnbrauer, Kidder and Tague, 1966).

This movement developed into a professional organization called The Society for the Experimental Analysis of Behavior (SEAB), founded in 1958. They began to publish a journal that would feature their work, The Journal of the Experimental Analysis of Behavior (JEAB). The journal was first published in 1958 with Ferster as its editor. Subsequently, the APA created a specific section, number 25, called the Section for Experimental Analysis of Behavior, in 1964.

\section{Characteristics of Applied Behavioral Analysis}

The Applied Behavior Analysis trend, created around Skinners' guidelines, had, as a main goal, the application of experimental analysis of behavior to modify abnormal behavior. Its principle characteristics included:

1) Behavior is controlled by environmental factors. To explain and control behavior, one must turn to the principles of reinforcement, punishment and extinction. The distinct techniques of Operant Conditioning are derived from these principles.

2) The object of study is the behavior of the organism and the methodological focus is the experimental analysis which means an obvious preference for the use of $\mathrm{N}=1$ investigation designs. However, the increasing use of multiple response evaluation strategies must be noted, and that although the $\mathrm{ABAB}$ design still predominated, the use of multiple and transverse base-line designs was becoming more and more frequent. Also, the general rejection of statistical analysis diminished at times, giving way for the use of appropriate statistical techniques for the case at hand, especially one subject analysis of variance and time series analysis. In any case, the central idea of the methodological focus of applied behavior analysis is the need to experimentally demonstrate that the change in behavior produced is due to the treatment. And so, the intra-subject design became the design of choice. (Kazdin, 1982; Hersen and Barlow, 1976; Kratochwill, Mott and Dodson, 1984).

3) The field of application, although very broad, presents two sub-areas in which applied behavior analysis is especially appropriate. Firstly, in treating subjects with limited or deteriorated cognitive capacity due to mental deficiency or drug or alcohol addiction, and those institutionalized with significant behavioral deficiencies. This area also includes subjects with histories of inadequate reinforcement which resulted in unadaptive behavior (chronic pain, depression, problems with their partners, etc.) The second sub-area includes modification of social or institutional environments: hospitals, prisons, classrooms and the work place.

Among the pioneering work done regarding the first subarea, we should mention that of Bijou (1955, 1957,1963); Bijou and Baer (1961, 1965); Bijou, Birnbrauer, Kridder and Tague (1966); Wolf, Risley and Mees (1964) and Wolf, and Risley (1971). Those relative to the second sub-area include Ayllon and Azrin (1968); O'Leary and O'Leary (1972); Ayllon, Garber and Pisor (1975); Walker and Buckley (1974) and Kazdin (1975). In general, we can find pioneering contributions to both areas, in Spanish, in studies by Ulrich, Stacknik and Mabry $(1966,1970)$ and more specifically, in the area of children, in work by Graziano (1971) and Ashen and Poser (1973).

4) Treatment should be evaluated on an experimental and therapeutic level (Risley, 1970). The first evaluation tries to determine if the treatment was successful or not by comparing the base data before and after. The second evaluation is directed towards determining the social and clinical relationships of the treatment results. The opinion of the person(s) living with the subject is extremely useful in this evaluation.

\section{Limitations}

Obviously, as in all scientific work, Skinner's proposal also has its limitations. Some of these limitations have actually held back the subsequent development of BM. Maybe it is not the most appropriate moment to emphasize the deficiencies of BM, but I consider this job incomplete without explaining this aspect. It is true that, maybe the most frequent criticism comes from non-psychology experts who make reference to such vague aspects as mechanicist vision of the people or lack of humanism. Also, the allegedly ethical character considered in a world under rigorous and inhumane control. It makes no sense to defend these allegations which result from a lack of knowledge regarding Skinner's work. However, we should point out some central aspects of his work that inhibited development, if not of theoretical aspects, of the psychological applications to the modification of human behavior. These aspects include: 
1. The discrete and atomistic nature of the units of analysis in terms of stimulus and response. The reality in many cases points to the impossibility or inappropriateness of the procedure. To isolate or discreetly consider a behavior, independent of the persons' other behaviors can, in some cases, make it easier to explain. However, in many other cases, it means a loss of important information about the determinants or causes of the behavior.

2. The lack of a conceptual representation of the individuals' history and the situational facts of the context and organism. It is true that Skinner points out the importance of a person's history to determine current behavior. However, when it is time to propose intervention, personal history is rarely taken into account, especially with standardized or group interventions.

3. The distinction of only two types of behaviors, reflex and operant, which are equivalent from a qualitative point of view. It is true that this idea is extremely practical, but also, to a certain degree reductionist and consequently limits the possibilities of evaluation and intervention of different human behaviors.

4. The explanation of human behavior and its determinants in terms of only one variable, reinforcement, which is basically applied to discrete_and repetitive units. Again, we consider what was stated in Point 1. Also, the presentation of only one explanatory principle leads it to be considered from an extraordinarily lax and ambiguous point of view. This makes its application possible to all kinds of behaviors and situations, but in consequence, resulting in a less operative capacity.

5. The consideration that the only relevant property of behavior is frequency. Although it does make the quantification of behaviors easier, it does not give relevance to other properties such as the morphology or duration of behavior. This could mean the loss of decisive information in many cases.

6. Analysis in terms of Antecedent-Response-Consequence is a simple linear relationship, but misleading. Relationships are not always so linear.

7. Absence of specific explanatory models for complex problems (each of the different disorders). Instead, he only explains one general model to explain all possible disorders, or specific models for each behavior. It is obvious that the presence of some similar behaviors can have functional value, and therefore a very different explanation in function of the combination of behaviors it appears with, systematically or sporadically.

8. Therapeutic solutions focus on modifying certain behaviors, but can this be considered therapy? Sometimes it's a question of modifying discrete behavior rather than modifiyng a disorder: it is not clear if reducing the hallucinations and developing new adaptive behaviors to the demands of the environment would be the same as overcoming a "psychotic bout".
In sum, this paper has have tried to emphasize the importance of Skinners' work to the development of BM. His work preceded BM, and collaborated in the creation of a sound body of laws regarding human behavior. His work in the beginning of BM indicated the path to follow, establishing new formulations about abnormal behavior and forms of intervention. His work in BM's first applications and its basic orientations, as well as his relevance as a agglutinative figure in this field of study, which continues to be effective and respected today, constitutes the most decisive contributions to the development of what we today call BM.

It is difficult to believe that one scientist has been able to change the knowledge base and practice of his discipline as radically as Skinner has. However, the analysis of his work obviously shows limitations. The best way to show our gratitude for the magnitude of Skinners work is to overcome his limitations. This is our current challenge.

\section{References}

Ashen, B., \& Poser, E. (Eds.). (1973). Adaptive learning: Behavior modification with children. New York: Pergamon

Ayllon, T. (1963). Intensive treatment of psychotic behavior by stimulus satiation and food reinforcement. Behavior Research and Therapy, 1, 53-61.

Ayllon, T., \& Azrin, N.H. (1965). The measurement and reinforcement of behavior of psychotics. Journal of the Experimental Analisis of Behavior, 8, 356-383.

Ayllon, T., \& Azrin, N.H.(1968). The token economy. New York: Meredith Corporation.

Ayllon, T., Garbes, S., \& Pisor, K. (1975). The elimination of discipline problems through a combined school-home motivational system. Behavior Therapy, 6, 616-626.

Ayllon, T., \& Haughton, E. (1964). Modification of symptomatic verbal behavior of mental patients. Behavior Research and Therapy, 2, 87-97.

Ayllon, T., \& Michael, J.(1959). The psychiatric nurse as a behavioral engineer. Journal of Experimental Analysis of Behavior, 2, 323-334.

Baer, D.M. (1962). Laboratory control of thumbsucking by withdrawal and re-presentation of reinforcement. Journal of Experimental Analysis of Behavior, 5, 525-528.

Barret, B.H. (1962). Reductions in rate of multiple tics by free operant conditioning methods. Journal of Nervous and Mental Disease, 135, 187-195.

Barret, B.H., \& Lindsley, O.R. (1962). Deficits in acquisition of operant discrimination in institutionalized retarded children. American Journal of Mental Deficiency, 67, 424-436.

Bijou, S.W. (1955). A systematic approach to an experimental analysis of young children. Child Development, 26,161-168.

Bijou, S.W. (1957). Pattern of reinforcement and resistance to extinction in young children. Child Development, 28, 47-54. 
Bijou, S.W. (1959). Learning in children. Monographs of the Society for Research in Child Development, 24, n 5.

Bijou, S.W. (1963). Theory and research in mental (development) retardation. Psychological Record, 13, 95-110.

Bijou, S.W., \& Baer, D.M. (1961). Child development. Vol.1. A systematic and empirical theory. New York: Appleton Century Crofts.

Bijou, S.W., \& Baer, D.M. (1965). Child development. Vol. 2. Universal stage of infancy. New York: Appleton Century Crofts.

Bijou, S.W., Birnbrauer, J.S., Kidder, J.D., \& Tague, C. (1966). Programmed instruction as an approach to the teaching of reading, writing and arithmetic to retarded children. Psychological Records, 16, 505-522.

Birnbrauer, J.S., Bijou, S.W., Wolf, M.M., \& Kidder, J.D. (1965). Programmed instructions in the classroom. In L.P. Ullman \& L. Krasner (Eds.), Case studies in behavior modification (pp.358-363). New York: Holt, Rinehart and Winston.

Dollard, J., \& Miller, N.E. (1950). Personality and psychotherapy: An analysis in terms of learning, thinking, and culture. New York: McGraw-Hill.

Eysenck, H.J. (1952). The effects of psychotherapy: An evaluation. Journal of Consulting Psychology, 16, 319-324.

Eysenck, H.J. (1957). The dynamics of anxiety and hysteria. London: Routledge and Kegan Paul.

Eysenck, H.J. (1965). The effects of psychotherapy. International Journal of Psychiatry, 1: 99-178

Eysenck, H.J. (1966). The effects of psychotherapy. New York: International Science Press.

Fester, C.B. (1953). The use of the free operant in the analysis of behavior. Psychological Bulletin, 50, 263-274.

Fester, C.B., \& DeMyer, M.K. (1961). The development of performances in autistic children in an automatically controlled environment. Journal of Chronic Disease, 13, 312-345.

Flanagan, B., Goldiamond, I., \& Azrin, N.H. (1958). The control of stuttering behavior through response-contingent consequences. Journal of Experimental Analysis of Behavior, 1, 173-177.

Fuller, P.R. (1949). Operant conditioning of a vegetative human organism. American Journal of Psychology, 62,587-590.

Graziano, A.M. (1971). Behavior therapy with children. Chicago: Aldine.

Hersen, M., \& Barlow, D.H. (1976). Single case experimental designs: Strategies for studying

behavior change. New York: Pergamon Press.

Kazdin, A.E. (1975). Behavior modification in applied settings. Homewood: Dorsey Press.

Kazdin, A.E. (1982). Single-case research design. New York: Oxford University Press.

Keller, F.S., \& Schoenfeld, W.N. (1950). Principles of psychology. New York: Appleton.

Krasner, L. (1955). The use of generalized reinforcers in psychotherapy research. Psychological Reports, 1, 19-25
Kratochwill, T.R., Mott, J.E., \& Dodson, C.L. (1984). Case study and single-case research in clinical and applied psychology. In A.S. Bellack \& M. Hersen (Eds.), Research methods in clinical psychology (pp55-99). New York: Pergamon Press.

Lindsley, O.R. (1956). Operant conditioning methods applied to research in chronic schizophrenia. Psychiatric Research Reports, $5,118-139$.

Lindsley, O.R. (1963). Free-operant conditioning and psychotherapy. Current Psychiatric Therapy, 3, 47-56.

Mayor, J., \& Labrador, F.J. (1984). Fundamentos teóricos y metodológicos de la modificación de conducta [Theroetical and methodological foundations of behavior modification]. In J. Mayor \& F.J. Labrador (Eds.), Manual de modificación de conducta (pp.9-92). Madrid: Alhambra.

O'Leary, K.D., \& O'Leary, S.E. (1972). Classroom management. New York: Pergamon Press.

Risley, T.R. (1970). Behavior modification. An experimental-therapeutic endeavor. In L.A. Hamerlynck, O.P. Davidson, \& L.E. Acker (Eds.), Behavior modification and ideal mental health services . University Calgary Press.

Sidman, M. (1960). Tactics of scientific research. New York: Basic Books.

Skinner, B.F. (1938). The behavior of the organisms. New York: Appleton.

Skinner, B.F. (1953). Science and human behavior. New York: McMillan

Skinner, B.F. (1954). A new method for the experimental analysis of behavior of psychotic patients. Journal of Nervous Mental Disease, 120, 403-406.

Skinner, B.F. (1957). Verbal behavior. New York: Appleton.

Skinner, B.F. (1961). Cumulative Record (Enlarged Edition). N.York: Appleton.

Skinner, B.F. (1963). Behaviorism at fifty. Science, 140, 951958.

Skinner, B.F. (1974). About Behaviorism. New York, Alfred A. Knopf

Skinner, B.R., Solomon, H.C., \& Lindsley, O.R. (1953). Studies in behavior therapy. Metropolitan State Hospital, Waltham, Massachusetts, Status Report I, $30^{\text {th }}$ November.

Skinner, B.R., Solomon, H.C., Lindsley, O.R., Richards, M.E. (1954). Studies in behavior therapy. Metropolitan State Hospital, Waltham, Massachusetts, Status Report II, 31th May.

Staats, A.W., Finley, J.R., Minke, K.A., \& WOLF, M.M. (1964). Reinforcement variables in the control of unit reading responses. Journal of the Experimental Analysis of Behavior, 7, 139-149.

Staats, A.W., Staats, C.K., Schutz, R.E., \& Wolf, M.M. (1962). The conditioning of textual responses using "extrinsic" reinforcers. Journal of the Experimental Analysis of Behavior, $5,33-40$.

Taffel, C. (1955). Anxiety and the conditioning of verbal behavior. Journal of Abnormal and Social Psychology, 51, 496-501.

Ulrich, R., Stacknik, T., \& Mabry, J. (1966). Control of human behavior. Vol. 1. Glenview: Scott, Foresman and Company. 
Ulrich, R., Stacknik, T., \& Mabry, J. (1970). Control of human behavior. Vol. 2. Glenview: Scott, Foresman and Company.

Walker, H.M., \& Buckley, N.K. (1974). Tokens reinforcements techniques. New York: Engelmann Becker.

Wilson, G.T., \& O'Leary, K.D. (1980). Principles of behavior therapy. Englewood Cliffs: Prentice-Hall.

Wolf, M.M., \& Risley, T. (1971). Reinforcement: Applied research. In R. Glase (Ed.), The nature of reinforcement. New York: Academic.
Wolf, M.M., Risley, T., \& Mees, H. (1964). Application of operant conditioning procedures to the behavior problems of an autistic child. Behavior Research and Therapy, 1, 305-312.

Yates, A.J. (1970). Behavior therapy. New York: Wiley.

Received July, 19, 2004

Revision received August, 24, 2004

Accepted September, 3, 2004 